\title{
Diseminación de Cuatro Virus de Papa en las Zonas de Mucuchíes, Estado Mérida y el Páramo de Cubiro, Estado Lara, Venezuela
}

\author{
Yorman Rodríguez, ${ }^{1}$ Eduardo Ortega, ${ }^{2}$ Gustavo Trujillo ${ }^{3}$
}

\begin{abstract}
Resumen
Se estudió la diseminación de los virus PLRV, PVY, PVX y PVS, en las zonas de Mucuchíes, estado Mérida y Cubiro, estado Lara, además de la fluctuación de áfidos y condiciones meteorológicas. La presencia de los virus se evaluó mediante la técnica serológica de ELISA. En Mucuchíes se evaluaron los cultivares Andinita y Granola de las clases Genética, Básica, Registrada, Certificada Nacional (N) y tipo Pasilla, incluyendo además para el segundo cultivar la clase Certificada Importada (I). Para Cubiro, los cultivares fueron Kennebec en las clases Genética, Certificada (N) y Certificada (I) y Sebago con Básica y Certificada (I). Para Granola se detectó alta frecuencia de PVS, PVX, PVX + PVY e infección triple (PVX + PVS + PVY), con los mayores porcentajes de PVS (12.5) en la clase Registrada, PVX (20.8) en Certificada (I) y de PVX + PVY (16.7) en Genética. En Andinita, la mayor frecuencia fue de PLRV, siendo el mayor porcentaje (29.2) en el tipo Pasilla. Para Cubiro, la mayor frecuencia fue de PVS, seguido de PVY en ambos cultivares. El mayor porcentaje de PVS (45.8) fue en Sebago Certificada (I) y 12.5 en Kennebec Certificada (I). En relación a la población de áfidos, en Mucuchíes se identificaron once especies, entre ellas Myzus persicae, Macrosiphum euphorbiae, Brachicaudus helichrysi, Rhopalosiphum padi y Brevicoryne brassicae, esta última la de mayor población, no registrada como vector de virus en papa. En Cubiro se capturaron diecinueve especies, incluyendo, además de las mencionadas anteriormente, la especie vectora de virus Aphis gossypii.
\end{abstract}

Aceptado para publicación: mayo 1997.

1 FONAIAP - Centro de Investigaciones Agropecuarias del Estado Lara.

2 FONAIAP Centro de Investigaciones Agropecuarias del Estado Monagas.

3 Universidad Central de Venezuela. 
Palabras claves adicionales: diseminación, virus, papa, tubérculos-

Semillas.

\title{
Dissemination of Four Potato Viruses in Mucuchíes, Mérida State, and El Páramo de Cubiro, Lara State, Venezuela
}

\begin{abstract}
Summary
A study of the dissemination of PLRV, PVY, PVX and PVS was carried out in Mucuchíes, Mérida State and Cubiro, Lara State, Venezuela. The fluctuation of aphid populations and meteorological conditions was also recorded. The presence of the viruses was evaluated using the ELISA serological technique. Andinita and Granola cultivars of the classes Genetic Basic, Registered, National Certified (N) and Pasilla (small tubers) were evaluated at Mucuchíes. For Granola the class Imported Certified (I) was also evaluated. In Cubiro, the cultivars evaluated were: Kennebec, classes Genetic Certified (N) and Certified (I), and Sebago classes Basic and Certified (I).
\end{abstract}

A high frequency of PVS, PVX, PVX+PVY and triple infection (PVX+PVS+PVY) was detected in Granola. The highest percent-ages were 12.5 of PVS in the Registered class, 20.8 of PVX in Certified (I) and 16.7 of PVX+PVY in Genetic class. In Andinita PLRV had the highest frequency with 29.2 in Pasilla. In Cubiro the highest frequency was for PVS followed by PVY in both cultivars. The highest percentage of PVS (45.8) was for Sebago Certified (I) and 12.5 for Kennebec Certified (I)

In the study of aphid population, eleven species were identified in Mucuchíes, including Myzus persicae, Macrosiphum euphorbiae, Brachicaudus helichrysi, Rhopalosiphum padi y Brevicoryne brassicae, the latter being the most numerous and not registered as a vector of potato viruses. In Cubiro, twenty species were captured and included, besides the species named above, Aphis gossypii as a virus vector.

Additional Index words: dissemination, virus, potato, seed-tubers. 
Uno de los factores más importantes para obtener buenos rendimientos en papa es el uso de semilla con bajos porcentajes de infección por virus. La sanidad viral de la semilla normalmente va de acuerdo a la clase de semilla dentro de un programa de certificación. Esta semilla se obtiene propagando plantas sanas en zonas donde la población de vectores es mínima.

En la actualidad se considera que en Venezuela el cultivo de la papa es atacado principalmente por los virus: $X(P V X), Y(P V Y), S$ (PVS), Virus del enrollamiento de las hoja (PLRV), y mosaico rugoso (PVX + PVY) (24). Es de gran importancia hacer notar la existencia probable de muchos otros debido a la gran introducción de tubérculos-semillas de papa al país. La selección de sólo estos cuatro virus como objetivo de nuestro estudio, obedece a su registro como los de mayor importancia desde el punto de vista económico, para Venezuela y el mundo (24). Su existencia en el país ha sido demostrada por muchos autores, causando tanto daños cualitativos como cuantitativos $(1,9,10,11,12,24)$.

Los estudios de investigación en virus de papa en Venezuela se han basado en el reconocimiento sintomatológico de las enfermedades, uso de plantas indicadoras y microscopía electrónica. Sin embargo, se desconoce bajo las condiciones de las diferentes regiones paperas del país, el orden de importancia y la frecuencia de aparición de estos virus; así como el papel que juegan las poblaciones de insectos vectores en su diseminación. Éste conocimiento es útil para tomar medidas de control y ayudar a determinar en qué período debe renovarse la semilla.

El presente trabajo tuvo como objetivos determinar la incidencia de los virus PVX, PVS, PVY, y PLRV en las diferentes clases de semillas producidas e importadas en las principales zonas de producción, así como determinar la relación que existe entre la población de áfidos alados y la diseminación de PVY y PLRV.

\section{Materiales y Métodos}

\section{Lugares de ejecución}

La investigación fue realizada en dos lugares ecológicamente diferentes: una zona de la cordillera andina, Mucuchíes en el estado Mérida y otra situada en la zona media, el páramo de Cubiro en el estado Lara. Mucuchíes se encuentra a una altitud de 3,100 msnm con una temperatura media anual de $11^{\circ} \mathrm{C}$. El páramo de Cubiro se encuentra a una altitud de $1,400 \mathrm{msnm}$ con una temperatura media anual de $13^{\circ} \mathrm{C}$. 


\section{Instalación de los experimentos}

\section{Tratamientos}

Se utilizaron 320 tubérculos por clase de semilla almacenados en condiciones de silo rústico, los cuales se llevaron al campo previamente preparado para ser sembrados como sigue: el cultivar Andinita con cinco tratamientos (clases: Genética, Básica, Registrada, Certificada, y tipo Pasilla) y el cultivar Granola con seis tratamientos de las clases: Genética, Básica, Registrada, Certificada nacional e importada y tipo Pasilla (tubérculos de siembras comerciales no sujetos a certificación). Los tubérculos fueron sembrados en ensayos separados, por condiciones de manejo de prácticas agronómicas y ciclo vegetativo de ambos. Los cultivares Kennebec con tres tratamientos (clases: Genética, Certificada nacional e importada) y Sebago con dos tratamientos (clases: Básica y Certificada importada), se sembraron en un solo ensayo por tener las mismas prácticas agronómicas y porque ambos son de ciclo corto.

\section{Diseño del experimento}

Los experimentos se sembraron el 18 de marzo de 1991 (Granola y Andinita) y el 29 de mayo de 1991 (Kennebec y Sebago). Fueron ubicados en bloques al azar con cuatro repeticiones. Cada tratamiento constó de cuatro surcos de $6 \mathrm{~m}$ de largo, colocando 20 tubérculos por surco, con separación de $1 \mathrm{~m}$ entre surco y entre bloque para los cultivares Andinita y Granola, y separación de $0.80 \mathrm{~m}$ entre surco y $1 \mathrm{~m}$ entre bloque para los cultivares Kennebec y Sebago.

\section{Evaluación de las poblaciones de áfidos}

\section{Trampas y su ubicación en el campo}

Para determinar la población de afidos alados, se utilizaron trampas de agua tipo Moericke modificadas mediante bandejas plásticas de color amarillo. Las trampas fueron colocadas al momento de la siembra en los extremos de cada ensayo y aproximadamente a $1 \mathrm{~m}$ del borde, tal como lo recomienda Cubillos, citado por Gandarillas (13). 


\section{Recolección e identificación de los afidos}

La recolección de áfidos se realizó una vez por semana, empleando pinceles y colocándolos en tubos de vidrio que contenían alcohol al 99\%. La identificación y el recuento de los áfidos capturados se realizó al estereoscopio basándose en la clave para la identificación de áfidos capturados en trampas en Venezuela (7).

\section{Evaluación de las parcelas experimentales}

Para realizar la detección de los cuatro virus en estudio de ambas localidades se hizo un análisis serológico de follaje. Se trabajó con una unidad de muestreo de los dos hilos centrales, que consistió en una muestra aleatoria de seis plantas por tratamiento y repetición, evaluando un total de 24 plantas por tratamiento. Para el cultivar Andinita se evaluaron 120 plantas (5 tratamientos), para Granola 144 plantas (6 tratamientos), Kennebec 172 plantas (3 tratamientos) y Sebago 48 plantas (2 tratamientos). En cada planta, utilizando bolsas plásticas se tomó un folíolo de la hoja de la parte superior, media e inferior formando una muestra compuesta por planta y se realizó serología por separado para cada virus, por la técnica de ELISA, según el procedimiento de Salazar (27). Las muestras para las pruebas serológicas se tomaron el 24 de julio de 1991 (Granola, el $1^{\circ}$ de julio de 1991 (Andinita) y el 15 de julio de 1991 (Kennebec y Sebago).

\section{Resultados y Discusión}

\section{Estado Mérida}

\section{Incidencia de PVX, PVS, PVY y PLRV en los diferentes tratamientos}

Para la zona de la cordillera andina en las muestras de follaje evaluadas para el cultivar Granola en las clases Genética, Básica, Registrada, Certificada (N), Certificada (I) y Pasilla, los resultados serológicos no mostraron PLRV en ninguno de los tratamientos. El PVX fue el virus que se encontró con mayor frecuencia, seguido del PVS y después el PVY.

En relación a la infección de PVX en el cultivar Granola se observó mayor porcentaje (20.8) en la clase Certificada (I), seguido de la clase Básica, tipo Pasilla y Genética (Tabla 1). La infección doble de PVX + PVY se presentó en $16.7 \%$ en Genética y $4.2 \%$ en Certificada (I). La clase Registrada y la Certificada (N) no presentaron infección. Con estos resultados serológicos de follaje se puede inferir que la infección de PVX en las diferentes clases de semilla ocurrió a nivel de campo durante el ciclo del experimento, debido a la fácil diseminación del virus cuando por efecto del viento, maquinarias 0 animales, las plantas rozan entre sí $(2,23)$, o por labores de aporque 0 
aplicación de productos químicos por el hombre, principal agente diseminador de PVX (21). Esta consideración obedece a que todo el material vegetativo utilizado fue chequeado previamente a la siembra por serología a nivel de brotes para los cuatro virus en estudio y la infección inicial fue de $0 \%$ para PVX, PVY y PLRV.

Tabla 1. Porcentaje de detección de virus en diferentes clases de semilla del cultivar Granola. Mucuchíes, Estado Mérida, Venezuela. 1991

\begin{tabular}{|c|c|c|c|c|c|c|}
\hline \multirow{2}{*}{$\begin{array}{c}\text { Clases de } \\
\text { semilla }\end{array}$} & \multicolumn{6}{|c|}{ Porcentaje de muestras infectadas ${ }^{\star}$} \\
\hline & PVX & PVS & PVY & PLRV & $P V X+P V Y$ & PVX+PVS+PVY \\
\hline Genética & 4.2 & 8.3 & 0 & 0 & 16.7 & 0 \\
\hline Básica & 8.3 & 0 & 8.3 & 0 & 0 & 0 \\
\hline Registrada & 0 & 12.5 & 0 & 0 & 0 & 4.2 \\
\hline Certificada (N) & 0 & 8.3 & 8.3 & 0 & 0 & 0 \\
\hline Certificada (I) & 20.8 & 4.2 & 0 & 0 & 4.2 & 0 \\
\hline Pasilla** & 8.3 & 12.5 & 4.2 & 0 & 0 & 0 \\
\hline
\end{tabular}

$\mathrm{N}=$ Nacional $\quad \mathrm{I}=$ Importada

Total de plantas $=24$

$* \%=N^{\circ}$ plantas infectadas $\times 100 / 24$

** Tubérculos de siembras comerciales no sujetas a certificación

Esta detección del PVX en el cultivar Granola en sus diferentes clases de semilla comprueba aún más la existencia del virus en el país, demostrada anteriormente en otros cultivares $(19,24)$.

Respecto al virus S, la clase Registrada y tipo Pasilla fueron las que presentaron mayor incidencia con tres muestras infectadas, seguida de la clase Certificada (N) y Genética ambas con dos muestras infectadas. La menor frecuencia fue en la Certificada (I) con una muestra infectada y no se detectó el virus en las muestras de la clase Básica. También se observa que el mayor porcentaje de infección (12.5) fue en Registrada además de $4.2 \%$ en infección triple (PVX + PVS + PVY). En pasilla se detectó 12.5\%, en Genética y Certificada (N) $8.3 \%$ y en Certificada (I) $4.2 \%$ (Tabla 1 ). 
Es importante señalar que el virus ya se encontraba en la semilla de las clases Certificada (N) e (I), resultado corroborado antes de la siembra por lo que los tubérculos infectados se consideran la principal fuente de inoculo (3). Los porcentajes de incidencia en los tratamientos Registrada, Pasilla y Genética, posiblemente se deben a infección de campo por labores culturales o contacto desde las parcelas de semillas de las clases Certificada o de una transmisión en forma no persistente por el áfido Myzus pérsicas (3, 21, 28, 30). EI PVS fue reportado en investigaciones anteriores en Venezuela en los estados Aragua, Carabobo y Mérida $(14,15,24)$.

El PVY se detectó con mayor frecuencia en las clases Básica y Certificada (N) con dos muestras infectadas y el tipo Pasilla con una muestra infectada. No se detectó PVY en las clases Genética, Registrada y Certificada (I). En la clase Básica y en Certificada se detectó 8.3\% y en el tipo Pasilla 4.2\% (Tabla 1).

Los análisis de los brotes previo a la siembra fueron serológicamente negativos para este virus, por lo que la infección primaria se debe a áfidos vectores (6). Este virus ha sido reportado en papa en el país por diferentes investigadores $(11,15,18)$, en los estados Aragua, Carabobo y Mérida.

En Granola para todas las clases de semilla y el tipo Pasilla la mayor incidencia fue infección simple con 18.1\%; luego infección doble con 3.5\% y por último infección triple con $0.7 \%$. El PVS presentó la mayor incidencia con once plantas infectadas, luego el PVX con diez y el PVY con cinco sobre 144 plantas evaluadas. La infección simple, doble y triple fue dada por los virus PVX, PVY y PVS. No se detectó PLRV probablemente por el nivel de resistencia de esta variedad a ese virus (31) y por la baja presión de los vectores.

En el cultivar Andinita el virus que se detectó con mayor frecuencia fue el PLRV en el tipo Pasilla, luego el PVX y el PVY. No se detectó PVS en ningún tratamiento. El porcentaje de infección observado para PLRV en el tipo Pasilla fue $29.2 \%$, además de $4.2 \%$ de infección doble PVX + PLRV. También se detectó $8.3 \%$ para la clase Registrada y $4.2 \%$ para Certificada (Tabla 2). Sin embargo, se debe tomar en cuenta el porcentaje de infección para PVX de 4.2 en la clase Certificada y 4.2 de PVY en la clase Básica, para evitar así la diseminación del virus por las razones ya expuestas en el cultivar Granola mediante el uso de técnicas de descriptores de plantas en los sistemas comerciales de semilla. EI PLRV fue reportado previamente en el país (10, 12, 23). 
Tabla 2. Porcentaje de detección de virus en diferentes clases de semilla del cultivar Andinita. Mucuchíes, Estado Marida, Venezuela. 1991.

\begin{tabular}{|lccccc|}
\hline & \multicolumn{5}{c|}{ Porcentaje de muestras infectadas y sanas* } \\
\cline { 2 - 6 } Clase de semilla & PVX & PVS & PVY & PLRV & PVX + PLRV \\
\hline Genética & 0 & 0 & 0 & 0 & 0 \\
Básica & 0 & 0 & 4.2 & 0 & 0 \\
Registrada & 0 & 0 & 0 & 8.3 & 0 \\
Certificada & 4.2 & 0 & 0 & 4.2 & 0 \\
Pasilla & 0 & 0 & 0 & 29.2 & 4.2 \\
\hline
\end{tabular}

* 24 plantas evaluadas por tratamiento.

** Tubérculos de siembras comerciales no sujetos a certificación.

Nota: La infección inicial para todas las clases de semillas y el tipo Pasilla fue $0 \%$.

De los resultados obtenidos se infiere que la infección de PLRV y PVY es primaria, debido a que el material chequeado previamente por brotes a nivel de laboratorio resultó serológicamente negativo y no es muy evidente una explicación al valor obtenido del PLRV en el tipo Pasilla. En relación al PVS se desconoce si la ausencia del mismo en esta variedad podría estar relacionada con un nivel de resistencia o por otros factores.

\section{Evaluación de la población de áfidos y su relación con la diseminación viral}

La mayor captura total de áfidos se presentó en los meses de febrero y marzo (época seca) donde se registró la menor precipitación; este hecho coincide con otras investigaciones (8). Es importante notar que a lo largo de los experimentos se registraron velocidades del viento superiores a $5 \mathrm{~km} / \mathrm{h}$ a $2 \mathrm{~m}$, temperatura promedio de $11.5 \%$ y humedad relativa fue $77 \%$. Por estas razones la baja población de áfidos (Tabla 3) puede deberse a las condiciones climáticas prevalentes en la zona de Mucuchíes que son desfavorables para estos insectos. 
Tabla 3. Especies de áfidos colectadas en trampas amarillas, durante el período febrero-setiembre. Mucuchíes, Mérida, Venezuela. 1991.

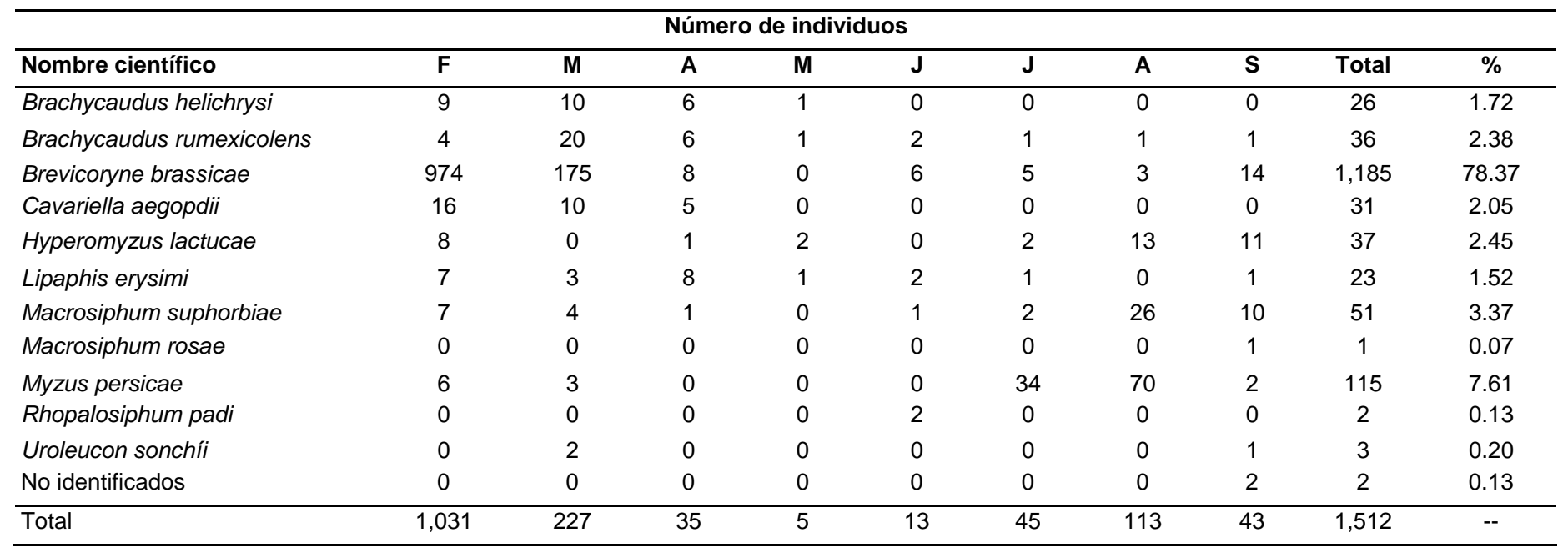

Vectores de PVY (a); PVY y PLRV(b); PVY, PLRV y PVS(c) 
Del total de áfidos capturados, Brevicoryne brassicae se encontró en 78.4\%; y su población fue mayor en los meses de febrero y marzo. Este áfido no es registrado como vector en virus en papa. La especie Myzus persicae se encontró en 7.6\%, Macrosiphum euphorbiae en 3.4\%, Brachycaudus helichrysi $1.7 \%$ y Rhopalosiphum padi en $0.1 \%$. La población de M. persicae fue la mayor entre las especies vectoras en los meses de julio, agosto y septiembre (Tabla 3); pero en un número total bajo que no permitió una diseminación viral amplia, por lo cual la incidencia de PLRV y PVY en la mayoría de los tratamientos fue baja entre $0 \%$ y $11.8 \%$ respectivamente para el cultivar Granola y $8.3 \%$ y $0.7 \%$ para el cultivar Andinita.

Es interesante destacar que esta máxima población de los vectores de PVY y de PLRV ocurre durante la época de cosecha de los experimentos a finales de julio (Granola) y a inicio de agosto (Andinita).

Se podría utilizar en la disminución de la diseminación viral del PLRV, la evasión y la resistencia por madurez (20) mediante la selección de épocas tempranas (febrero) de plantación en las explotaciones destinadas a la producción de las diferentes clases de semilla.

\section{Estado Lara}

\section{Incidencia de PVX, PVS, PVY y PLRV en los diferentes tratamientos}

Para la zona intermedia se encontró con mayor frecuencia el PVS, seguido en menor proporción por el PVY, PVX y PLRV. Los tratamientos se mostraron diferentes en cuanto a la presencia de PVS, y similares a la presencia de PVY. La incidencia de PVS fue $45.8 \%$ en Sebago Certificada (I), $8.3 \%$ de PVS + PVY y 8.3\% de PVY. En Kennebec Certificada (I), se detectó $12.5 \%$ de PVS, $4.2 \%$ de PVX, PVY y PLRV, respectivamente, además $4.2 \%$ de PVY en Genética (Tabla 4). Las diferencias apreciables en cuanto a la presencia del PVS son atribuibles a la fácil diseminación bajo las condiciones ecológicas del páramo por el porcentaje de infección inicial en el material importado y a la susceptibilidad de estas variedades a ese virus. 
Tabla 4. Porcentaje de detección de virus en diferentes clases de semilla de los cultivares Kennebec y Sebago. Cubiro, Estado Lara, Venezuela. 1991.

\begin{tabular}{|c|c|c|c|c|c|c|}
\hline \multirow[b]{2}{*}{ Cultivar } & \multirow{2}{*}{$\begin{array}{l}\text { Clases de } \\
\text { semillas }\end{array}$} & \multicolumn{5}{|c|}{ Porcentaje de muestras infectadas y sanas* } \\
\hline & & PVX & PVS & PVY & PLRV & PVX + PLRV \\
\hline \multirow{3}{*}{ Sebago } & Básica & 0 & 0 & 0 & 0 & 0 \\
\hline & Certificada (I) & 0 & 45.8 & 8.3 & 0 & 8.3 \\
\hline & Genética & 0 & 0 & 4.2 & 0 & 0 \\
\hline \multirow[t]{2}{*}{ Kennebec } & Certificada (N) & 0 & 0 & 0 & 0 & 0 \\
\hline & Certificada (I) & 4.2 & 12.5 & 4.2 & 4.2 & 0 \\
\hline
\end{tabular}

$\mathrm{N}=$ Nacional $\quad \mathrm{I}=$ Importada $\quad$ Total de plantas $=24$

Nota: La infección inicial fue de 0\% para PVX, PVY y PLRV.

El alto porcentaje de infección del PVS en esta zona amerita tener cuidado al momento de una nueva siembra por la diseminación del virus, debido a la característica frecuente de obtener plantas asintomáticas y a que los productores guardan semilla para siembras sucesivas provenientes de plantaciones donde el material inicial es clase Certificada. La incidencia de PVY en ambos cultivares se debe a una infección temprana ya que el muestreo de serología se realizó antes de la floración y se observó la presencia de áfidos alados entre ellos el vector Myzus persicae. En los dos tratamientos del cultivar Sebago se detectó $27.1 \%$ de infección simple especialmente por PVS y $4.2 \%$ de infección doble (PVS y PVY). Para el cultivar Kennebec se detectó solamente $9.7 \%$ de infección simple y no se determinaron infecciones dobles, triples y cuádruples.

\section{Evaluación de la población de áfidos y su relación con la diseminación viral}

Se identificaron 19 especies, de los cuales se informa sobre 8 transmisoras de PVY: Aphis gossypii Glover (5), Aspiraecola spp. Pathy (6), Brachycaudus helichrysi Kaltenbach (5), Hyperomyzus lactucae L. (5), Liphaphis erisymi Kaltenbach (5), Rophalosiphum padi L. (5), Raphosiphum maidis (16) y Uroleucon sonchi L. (15). Cuatro especies han sido registradas como vectoras de PVY y PLRV: Aphis chaccivora Koch (17), Aphis fabae Scopoli (5), Aulacorthum solani Kaltenbach (5), Macrosiphum euphorbiae Thomas (5), Myzus persicae Sulzer se cita como vector de PLRV, PVY y PVS $(5,9)$. Por último se identificaron 6 especies que no han sido mencionadas como vectoras de virus de papa: Aphis coreopsides Thomas, Acyrtosiphon bidenticola Smith, Amporophora commerlirensis Smith, Brevicoryne brassicae L., Rhopalosiphum 
rufiabdominalis Sasaki y Uroleucon ambriosae Thomas.

El cómputo de la población de áfidos no fue posible debido a la irregularidad de las capturas. Es importante observar que durante el período del experimento se registraron velocidades de viento a $0.5 \mathrm{~m}$ desde $3 \mathrm{~km} / \mathrm{h}$ y a $2.0 \mathrm{~m}$ desde $7 \mathrm{~km} / \mathrm{h}$. La temperatura promedio de $18^{\circ} \mathrm{C}$ y humedad relativa de $80.2 \%$. Estas condiciones son favorables para el desarrollo de la población de estos insectos, el vuelo, así como la migración de un cultivo de papa a otro $(8,25)$. Sin embargo, se presenta una situación similar a la del estado Mérida donde los valores de incidencia de PVY y PLRV son bajos por la calidad fitosanitaria de las semillas utilizadas y debido probablemente a baja fuente de inoculo externo.

\section{Comparación Entre las Dos Zonas}

\section{Similitud y diferencia entre las zonas}

En relación a la similitud, los virus más difundidos son los que se transmiten por contacto (PVX, PVS), especialmente el virus $S$ de la papa. También se destaca este virus en ambas zonas en la semilla importada del cultivar Granola, Kennebec y Sebago (Tabla 5). Estos virus con frecuencia son asintomáticos y normalmente alcanzan altas concentraciones por lo que pueden detectarse eficientemente con la prueba serológica de ELISA.

Debe considerarse como prioritario a estos virus en el programa de producción de semilla, debido a que la alta incidencia de los mismos puede significar un problema en términos de reducción de rendimiento por la alta probabilidad de infecciones simples, como fue observado en los resultados de ambas zonas.

En cuanto a las diferencias de las zonas, se explican en parte por las diferencias varietales y condiciones ambientales. En cada zona se siembran cultivares con características de mayor o menor susceptibilidad a la infección con virus específicamente los transmitidos por insectos vectores. Es el caso del cultivar Andinita que resultó con mayor infección de PLRV en la zona Andina en contraste con el cultivar Granola que se mostró resistente a este virus. Una situación inversa se presentó para la infección con PVY donde el cultivar Andinita demuestra algún grado de resistencia. 
Tabla 5. Porcentaje de infección de virus en diferentes cultivares de papa. Venezuela. 1991.

\begin{tabular}{lcccc}
\hline \multirow{2}{*}{\multicolumn{1}{c}{ Infección }} & \multicolumn{2}{c}{ Zona andina } & \multicolumn{2}{c}{ Zona intermedia } \\
\cline { 2 - 5 } Simple & Granola & Andinita & Sebago & Kennebec \\
PVX & & & & \\
PVS & 6.9 & 0.8 & & 1.4 \\
PVY & 7.6 & & 22.9 & 4.2 \\
PLRV & 3.5 & 0.8 & 4.2 & 2.8 \\
\hline Doble & & 8.3 & & 1.4 \\
PVX + PVY & & & & \\
PVX + PLRV & 3.5 & & & \\
\hline Triple & & & & \\
PVX + PVS + PVY & 0.7 & & & \\
\hline
\end{tabular}

Se destaca que el cultivar Granola no se siembra en el estado Lara y que las preferencias de los agricultores se ha orientado hacia los cultivares Kennebec y Sebago que mostraron susceptibilidad a estos virus.

Las infecciones múltiples que ocasionaron severas disminuciones de rendimiento (4) como PVX + PVY y la combinación PVX + PLRV sólo se obtuvieron en los cultivares Granola y Andinita respectivamente y sólo se determinó una infección triple (PVX + PVS + PVY) (Tabla 5) en Granola; esto está indudablemente relacionado con el nivel de resistencia de las variedades a los virus mencionados, y al bajo nivel de inoculo inicial. Aún cuando se presentaron infecciones simples para los cuatro virus en el cultivar Kennebec, no se tiene una explicación consistente para la ausencia de las infecciones múltiples por contacto, dado que el amplio desarrollo de las plantas y el manejo agronómico intensivo del sistema de producción facilitan el frecuente contacto de las plantas.

Las condiciones ecológicas de ambas zonas podrían explicar este fenómeno. El páramo de Cubiro parece dar una mejor aclimatación para la población de áfidos y esto se observó con la captura de 13 especies vectoras en dicha zona y de 8 especies vectoras en Mucuchíes. Lo que obligaría a tener mayor cuidado en la multiplicación de las semillas en aquella zona si se parte de niveles de calidad fitosanitaria similares. Sin embargo, debe destacarse la variabilidad en la eficiencia de transmisión de los vectores (5), dado los bajos valores de PVY en Kennebec y Sebago. 
La población de vectores de estos virus, en los ambientes de zonas altas es mucho menor que en zonas más bajas (22). Otros estudios realizados en un cultivar de $S$. tuberosum spp. Andigena en diferentes alturas en el Perú demostraron que la variación de incidencia de PLRV se debió a las diferencias en la presión del inoculo (26). Los resultados en cuanto al PLRV están por lo tanto fuertemente influenciados por la susceptibilidad de la variedad Andinita.

Según la investigación realizada en Mucuchíes no se puede descartar que $B$. brassicae, por su alta población en las condiciones de la zona, sea vector de algunos de los virus en estudio, lo que amerita una posterior investigación.

En este sentido, la presencia de los virus anteriormente señalados en las diferentes clases de semilla justifica la necesidad de un manejo cuidadoso y un seguimiento en las diferentes etapas del proyecto de producción de tubérculos-semillas; y así evitar una rápida diseminación de los mismos porque de la zona Andina se distribuyen diferentes clases de semilla al estado Lara.

También es importante evaluar la incidencia de cada virus en cada localidad en relación al efecto sobre la disminución de los rendimientos. Los datos publicados en el país se refieren a una merma del $49 \%$ por la infección secundaria del PLRV en el cultivar Sebago (10).

Los autores expresan su sincero agradecimiento al Dr. Oscar Hidalgo del Centro Internacional de la Papa (CIP), por las sugerencias y el apoyo en el planteamiento y desarrollo del trabajo, y al Programa de las Naciones Unidas para el Desarrollo (PNUD) por el apoyo financiero.

\section{Referencias Bibliográficas}

1. Achutegui, B.A. 1982. Caracterización y huéspedes alternos del virus "X" de la papa. Tesis Ing. Agr. Facultad de Agronomía. UCV, Maracay, Venezuela. $53 \mathrm{p}$.

2. Beemster, A.B.R., J.A. de Bokx. 1987. Survey of properties and symptoms. En: Viruses of potatoes and seed potato production. J.A. de Bokx, J.P.M. and Van der Want (ed.). 2da. Ed. Wageningen, Center for Agricultural Publishing and Documentation. p. 84-113.

3. Bagnall, R.H. 1980. Virus S. En: Hooker. W. (ed). Compendio de enfermedades de la papa. Trad. Teresa Ames de Icochea. Lima, Centro Internacional de la Papa. p. 105-106. 
4. Bokx, J.A. 1980. Mosaico rugoso, mosaico severo. En: Hooker, W. Ed. Compendio de enfermedades de la papa. Trad. Teresa Ames de Icochea. Lima, Centro Internacional de la Papa. p. 98-100.

5. Bokx, J.A. 1987. Biological properties. En: Bokx, J.A. y Van der Wants, J.P.H. Viruses of potato and seed potato production. Wageningen. P. 58-82.

6. Carlebach, R.; Raccah, B.; Lobenstein, G. 1982. Detection of potato virus $\mathrm{Y}$ in the aphid Myzus persicae by ELISA. Ann. Appl. Biol. 101:511516.

7. Cermeli, M. 1984. Clave para la identificación de áfidos capturados en trampas en Venezuela. FONAIAP, CENIAP, Maracay. Serie AN 2-20. $175 p$.

8. Cermeli, M. 1970. Los áfidos de importancia agrícola en Venezuela y algunas observaciones sobre ellos. (Homoptera: Aphididae). Agronomía Tropical. 20(1):15-63.

9. Debrot, E.A.; Lastra, R.; Ladera, P. 1980. El virus "X" de la papa en Venezuela. Rev. Fac. Agronomía. UCV (Maracay). 11(1-4):63-77.

10. Debrot, E.A.; Lastra, R.; Ladera, P. 1975. El virus del enrollamiento de las hojas de papa (Potato Leaf Roll) en Venezuela. Agronomía Tropical. Venezuela. 25(2): 107-116.

11. Escobar, M.L. 1982. Caracterización y huéspedes alternos del virus "Y" de la papa. Tesis Ing. Agr. UCV, Maracay, Venezuela. 32 p.

12. Farro, A. 1977. Diagnóstico sintomatológico del virus del enrollamiento de la papa en las zonas Anzoátegui y Guárico del estado Lara. Fitopatología (Perú). 12(2):51.

13. Gandarillas, A.A. 1986. Diseminación de algunos virus de papa en la zona de Huancayo e Ica. Tesis Mg.Sc. Universidad Nacional Agraria. Lima, Perú. 68 p.

14. Gaskin, A.D.M. 1981a. Confirmación de la presencia de los virus S y M de la papa en Venezuela. En: Seminario Nacional de Fitopatología. (7, San Cristóbal, Ven.) [Comprendió de trabajos presentados]. San Cristóbal, Sociedad Venezolana de Ingenieros Agrónomos, Sociedad Venezolana de Fitopatología, p.58.

15. Gaskin, A.D.M. 1981b. Virus comunes en papa en diferentes localidades de los estados Aragua, Carabobo y Mérida. En: Seminario Nacional de Fitopatología. (7, San Cristóbal, Ven.). [Compendio de trabajos 
presentados]. San Cristóbal, Sociedad Venezolana de Ingenieros Agrónomos, Sociedad Venezolana de Fitopatología, p.58-59.

16. Gonda y Reddy. 1989. Aphid transmitted viruses infecting chille. Current Research University of Agricultural Science 18:71-72.

17. Halbert, S.; Corsini, D.; Sandobal, L 1994. Transmission of potato virus $Y$ by common aphids in Idaho. Am. Potato J. 71(10):675.

18. Herold, F. 1964. Investigaciones sobre virus de plantas. Acta Científica Venezola. 15(2)60-70.

19. Hooker, W.J. 1982. Enfermedades virosas de la papa. Boletín de Información Técnica 19. Lima, Perú. Centro Internacional de la Papa(CIP). 17p.

20. Knutson, K.W.; Bishop, G.W. 1964. Potato Leaf Roll - Effect of date of inoculation on percent infection and symptom expression. Am. Potato J. 41:227-238.

21. Koenig, R. 1982. Carlavirus group. C.M.I./A.A.B. Descriptions of plant viruses. No. 259. 4 p.

22. Jones, R.A.C. 1981. The ecology of viruses infecting wild and cultivated potatoes in the Andean region of South America. In: J.M. Thresh (ed.). Pest, pathogens and vegetation. The role of weed and wild plants in the ecology of crop pests and diseases. Pitman Advanced Publishing Program. Boston, p. 89-107.

23. Munro, J. 1961. The importance of potato virus X. Am. Potato J. 38:440447.

24. Ortega, C.E. 1988. Enfermedades causadas por virus. En: Producción de semilla de papa y transferencia de tecnología en Venezuela. FONAIAP, Venezuela, p. 105-203.

25. Raman, K.V. 1985. Transmisión de virus de papa por áfidos. Boletín de Información Técnica 2. Centro Internacional de la Papa (CIP). Lima, Perú. 22 p.

26. Rodríguez, A.; Jones, R.A.C. 1978. Enanismo amarillo - Disease of Solanum andigena potatoes is caused by Potato Leaf Roll Virus. Phytopathology: 68:39-43.

27. Salazar, L.F. 1983. Detección con ELISA de virus en papa. Centro Internacional de la Papa (CIP). Serie II, Guía 11/3. Lima, Perú. 11 p.

28. Slack, S.A. 1983. Identification of an isolate of the Andean strain of potato virus $S$ in North America. Plant Disease 67:786-789. 
29. Wardrop, E.A.; Gray, A.B.; Singh, R.P.; Peterson, J.F. 1989. Aphid transmission of potato virus S. Am. Potato J. 66:449-459.

30. Wetter, C. 1971. Potato virus S. C.M.I./A.A.B. Descriptions of plant viruses. No. 60. 3 p.

31. Zumbado, A. 1987. Evaluación de variedades y clones de papa en la región papera de Cartagena, Costa Rica. En: Reunión Asociación Latinoamericana de la Papa. (Memorias), Panamá, p. 22-26. 